\title{
Metadata Correction: Direct Adherence Measurement Using an Ingestible Sensor Compared With Self-Reporting in High-Risk Cardiovascular Disease Patients Who Knew They Were Being Measured: Prospective Intervention
}

David Thompson ${ }^{1}$, MRCPI; Teresa Mackay ${ }^{2}, \mathrm{RN}$; Maria Matthews², RN; Judith Edwards², RN; Nicholas S Peters ${ }^{3}$, MD, FRCP, FHRS; Susan B Connolly ${ }^{3}$, MRCPI, PhD

\footnotetext{
${ }^{1}$ International Centre for Circulatory Health, National Heart and Lung Institute, Imperial College London, London, United Kingdom

${ }^{2}$ Imperial College Healthcare NHS Trust, London, United Kingdom

${ }^{3}$ National Heart and Lung Institute, Imperial College London, London, United Kingdom
}

\section{Corresponding Author:}

Nicholas S Peters, MD, FRCP, FHRS

National Heart and Lung Institute

Imperial College London

4th Floor Imperial Centre for Translational and Experimental Medicine

Du Cane Road

London, W12 0NN

United Kingdom

Phone: 442075941880

Fax: 442075941880

Email: n.peters@imperial.ac.uk

\section{Related Article:}

Correction of: http://mhealth.jmir.org/2017/6/e76/

(JMIR Mhealth Uhealth 2018;6(4):e13) doi: 10.2196/mhealth.8317

In the paper by David Thompson et al, "Direct Adherence Measurement Using an Ingestible Sensor Compared With Self-Reporting in High-Risk Cardiovascular Disease Patients Who Knew They Were Being Measured: A Prospective Intervention" (JMIR Mhealth Uhealth 2017;5(6):e76), author Nicholas S Peters's middle name initial was omitted.
The author's name has been corrected and the corrected article will appear in the online version of the paper on the JMIR website on April 27, 2018, together with the publication of this correction notice. Because this was made after submission to PubMed, Pubmed Central, and other full-text repositories, the corrected article also has been re-submitted to those repositories.

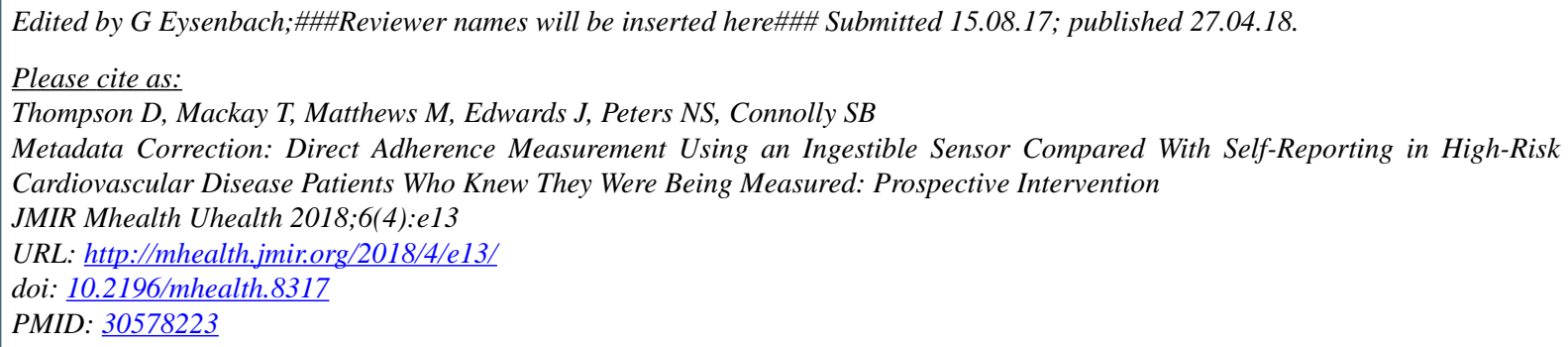

(CDavid Thompson, Teresa Mackay, Maria Matthews, Judith Edwards, Nicholas S Peters, Susan B Connolly. Originally published in JMIR Mhealth and Uhealth (http://mhealth.jmir.org), 27.04.2018. This is an open-access article distributed under the terms of the Creative Commons Attribution License (https://creativecommons.org/licenses/by/4.0/), which permits unrestricted use, 
distribution, and reproduction in any medium, provided the original work, first published in JMIR mhealth and uhealth, is properly cited. The complete bibliographic information, a link to the original publication on http://mhealth.jmir.org/, as well as this copyright and license information must be included. 